\title{
ANALISIS FAKTOR EKSTERNAL PENGGERAK DINAMIKA KURS US DOLLAR DAN IMPLIKASINYA TERHADAP PEREKONOMAN INDONESIA
}

\author{
Oleh: \\ Wiriadi Sutrisno ${ }^{1}$ \\ Dona Fitria ${ }^{2}$ \\ Siswi Wulandari ${ }^{3}$ \\ Dosen Program Studi Pendidikan Ekonomi \\ Fakultas Ilmu Pendidikan dan Pengetahuan Sosial \\ Universitas Indraprasta PGRI \\ Email: \\ wiriadisutrisno@gmail.com ${ }^{l}$
}

\begin{abstract}
ABSTRAK
Kajian ini akan menguraikan faktor eksternal penggerakkan dinamika US Dollar yang secara langsung berpengaruh terhadap tingkat perekonomi Indonesia. Dinamika pergerakan US Dollar di Indonesia ditandai dengan kecendrungan naik dan turunnya nilai kurs dollar terhadap nilai Rupiah, merupakan indikator kestabilan atau tidaknya kondisi perekonomian suatu negara khususnya Indonesia dan menjadi pertimbangan utama bagi para investor asing yang akan melakukan investasi. Fenomenakrsis perekonomian di Eropa, Amerika, Tiongkok bahkan kondisi politik di Yunani merupakan sebagian dari faktor eksternal yang mempengaruhi dinamika UD dollar dan perekonmian Indonesia. Alat analisis yang digunakan dalam kajian ini adalah metode statistika deskriptif yang dapat menjawab hypotesa tentang dinamika US dollar, dengan menampilkan tabel dan angka statitik yang jelas dan kesimpulan yang yang jelas tentang seberapa kuat pengaruh faktor eksternal terhadap dinamika US dollar di Indonesia.

Kata Kunci: Dinamika US Dollar, Faktor Eksternal, Metode Statistika Deskriptif.
\end{abstract}




\section{A. PENDAHULUAN}

Pergerakan atau dinamikan Kurs US dollar di Indonesia akan mencerminkan kondisi perekonomian yang signifikan bagi iklim investasi bagi para investor asing. Dinamika Kurs US dollar yang di tandai dengan fluktuasi dalam perkembangan nilai tukar mata uang akan mengakibatkanperubahan perilaku economic agent dalam keputusan berbisnis. Pergerakan nilai tukar yangovervalued, akan berimplikasi pada semakin mahalnya harga barang impor dalam persepsimata uang domestik. Hal ini akan berdampak pada semakin berkurangnya daya beli importirdalam pemenuhan kebutuhan produknya. Sebaliknya manakala terjadi undervalued, maka bagieksportir hal tersebut akan dapat mengurangi margin profit yang diterimanya dari produk yanglaku di pasar internasional.Dampak pergerakan nilai tukar mata uang terhadap perilaku economic agent (eksportir dan impor) dapat dijelaskan melalui besarnya biaya dan harga yang muncul dari volatilitas nilaitukar.

Ada beberapa faktor yang menyebabkan dinamika kurs dollar. Penyebab popular yang dijadikan alasan bagi para analis, kususnya yang berada dilantai bursa adalah faktor eksternal dan internal, yang secara signifikan digerakkan oleh fundamental faktor dan teknikal faktor, yang antara lain ditandai dengan pergerakan Prime Rate pada Bank Sentral AS (Federal Reserve atau The Fed), kenaikan harga minyak dunia, merosotnya harga saham dunia, merosotnya kondisi perkonomia negara negara adidaya dunia, issu sentimen negatif baik politikmaupun ekonomi dari suatu negara, khususnya negara-negara yang mata uangnya ada pada currencies bucket. Dalam memilih faktor eksternal, peneliti memberi batasan batasan, antara lain melemahnya kondisi perekonomian negara negara Eropa, krisis fiskal AS, data Ekonomi AS yang membaik, menurunnya harga minyak dunia, strategi Tiongkok melemah kan Yuan.

\section{B. KAJIAN PUSTAKA}

\section{Kajian Teori Ekonomi Makro}

Dalam hal ini, menurut Baldwin dan Meir (1989) dalam Mukhlis (2011), mengatakan bahwa biaya yang dibutuhkan oleh economicagent untuk masuk ke pasar tersebut merupakan sunk cost. Adanya volatilitas nilai tukar, tidakserta merta menyebabkan economic agent langsung ke luar dari pasar. Economic agent akanmenunggu saat yang tepat dimana marjin keuntungan yang diperolehnya belum pada kondisi negatif (rugi). Selanjutnya menurut Baldwin dan Krugman tersebut pada kondisi terjadinya volatilitas tersebut, terdapat hubungan asimetris antara nilai tukar yang trigger entry and exitinto the export market. Pergerakan nilai tukar yang berfluktuasi di pasar uang tersebut akan sangat ditentukanoleh sistem nilai tukar yang dianut oleh masing-masing negara. Sistem nilai tukar mata uangyang bersifat fixed exchange rate, cenderung akan mengakibatkan stabilitas nilai tukar matauang karena adanya supporting dari otoritas moneter dalam bentuk intervensi di pasar uang.

Di pihak lain, sistem nilai tukar mata uang yang menganut floating exchange rate akan cenderung mengakibatkan pergerakan nilai tukar mata uang yang bersifat volatil. Pada jenis nilai tukarmata uang yang bersifat volatil ini, 
membawa konsekuensi pada kondisi ketidakpastian yang akan dihadapi oleh economic agent. Ketidakpastian tersebut merupakan teka-teki yang patutdicermati oleh semua fihak dalam menjaga stabiliatas makro ekonomi. Dalam hal ini Krugman dalam Adam, (1991) memberikan penjelasan yang menarik tentang adanya significant puzzle dalam perilaku nilai tukar mata uang dan harga suatu barang. Menurutnya volatilitas nilai tukar mata uang nominal yang sangat tinggi dapat mendorong adanya muted reaction terhadap harga barang riil dan hal ini dapat membawa konsekuensi pada kecilnya penyesuaian dalam volume barang yang diperdagangkan. Sehingga dengan demikian, pada dasarnya menurut pemikiran Krugman tersebut volatilitas nilai tukar mata uang tidak berpengaruh secara cepat terhadap harga.

Dalam pemikiran lain Krugman juga menjelaskan bahwa adanya sunk cost akan mendorongvariabilitas pergerakan nilia tukar mata uang. Dalam modelnya yang dikenal dengan hysteresis model, dijelaskan bahwa sekali nilai tukar mata uang bergerak dengan sejumlah tertentu entry dan exit yang akan terjadi di pasar. Pandangan utama Krugman adalah marjin pada kejadian hyeteresis akan berbeda dengan sejumlah variabiltas nilai tukar yang terjadi. Nilai tukar mata uang yang terjadi sebelumnya akan digunakan untuk membentuk ekspektasi tentang perubahannilai tukar. Semakin besar volatilitas nilai tukar sekarang akan berdampak pada semakin besarnya volatilitas di masa depan.

Pada sisi lain Baldwin (1988) juga menjelaskan bahwa berdasarkan bukti empiris yangdiperolehnya menunjukkan adanya sebuah puzzle tentang importprice sluggishness dan hal tersebut mengakibatkan terjadinya hysteresis dalam keputusan keluar masuk pasar. Dalam hal ini pada dasarnya Krugman tidak menjelaskan secara riil adanya price sluggshness. Nilai tukar mata uang yang berada pada posisi rendah (low level) pass through dari nilai tukar dari impor barang membutuhkan penjelasan. Dalam hal ini Baldwin mengajukan penggunaan idea of path dependence di perusahaan yang memiliki keputusan harga secara langsung. Selain itu pula dalam penjelasannya Baldwin juga menjelaskan adanya hubungan terbalik antara the size ofthe pass through dan volatilitas dari nilai tukar mata uang. Sedangkan pemikiran Krugman tidak fokus secara khusus pada passthrough elasticity.

Dalam teori histeresis model Baldwin dan Krugman tersebut pada dasarnya dinyatakan bahwa ... unexpected bilateral exchange rate misalignment can cause a permanent changein market structure (Baldwin, 1988; Baldwin dan Krugman, 1989). Dalam hal ini model histeresisdan bukti empiris menunjukkan bahwa perubahan dalam nilai tukar membawa perbedaan dalam dampak terhadap berbagai sektor, tergantung karakteristik khusus dari setiap industri. Karakteristik tersebut seperti investasi awal (Baldwin, 1988), tingkat substitusi barang (Dornbusch, 1987) dan ada tidaknya produk yang durable (Foot dan Klemperer, 1989).

\section{Kebijaksanaan Pemerintah}

Dalam menciptakan kondisi perekonomian yang kondusif, Pemerintah melalui Bank Indonesia mempunyai satu tujuan tunggal yakni mencapai dan menjaga kestabilan nilai rupiah. Hal ini mengandung dua aspek yakni kestabilan 
nilai mata uang rupiah terhadap barang dan jasa yang tercermin pada laju inflasi; serta kestabilan nilai mata uang rupiah terhadap mata uang negara lain yang tercermin pada perkembangan nilai tukar. Dari segi pelaksanaan tugas dan wewenang, Bank Indonesia menerapkan prinsip akuntabilitas dan transparansi melalui penyampaian informasi kepada masyarakat luas secara terbuka melalui media massa setiap awal tahun mengenai evaluasi pelaksanaan kebijakan moneter, dan serta rencana kebijakan moneter dan penetapan sasaran-sasaran moneter pada tahun yang akan datang. Informasi tersebut juga disampaikan secara tertulis kepada Presiden dan DPR sesuai dengan amanat Undang-Undang.Berdasarkan Undang-Undang Republik Indonesia Nomor 3 Tahun 2004 tentangPerubahan Atas Undang-Undang Republik Indonesia Nomor 23Tahun 1999 tentang Bank Indonesia, pada pasal 10, Bank Indonesia berwenang: 1) Menetapkan sasaransasaran moneter dengan memperhatikan sasaran laju inflasi; 2) Melakukan pengendalian moneter dengan menggunakan cara cara yang termasuk tetapi tidak terbatas pada: a) Operasi pasar terbuka di pasar uang baik rupiah maupun valuta asing; b) Penetapan tingkat diskonto; c) Penetapan cadangan wajib minimum; d) Pengaturan kredit atau pembiayaan.

\section{Dinamika Kurs US Dollar}

Pergerakan kurs dibentuk oleh beberapa faktor-faktor ekonomi dan faktor non-ekonomi, diantaranya: suku bunga, jumlah uang beredar, dan neraca pembayaran (faktor-faktor ekonomi), dan keamanan, keadaan politik, tingkat korupsi, serta lain-lain (faktor-faktor non ekonomi). Perbedaan nilai tukar mata uang suatu negara (kurs) pada prinsipnya ditentukan oleh besarnya permintaan dan penawaran mata uang tersebut Levi (1996), Akibatnya timbul depresiasi dan apresiasi. Depresiasi mata uang negara membuat harga barang-barang domestik menjadi lebih murah bagi pihak luar negeri. Sedang apresiasi rupiah terhadap dollar AS adalah kenaikan rupiah terhadap dollar AS. Apresiasi mata uang suatu negara membuat harga barangbarang domestik menjadi lebih mahal bagi pihak luar negeri Sukirno (2014). Dinamisasi dari pergerakan kurs dan fluktuasinya dapat terlihat pada grafik dibawah ini.

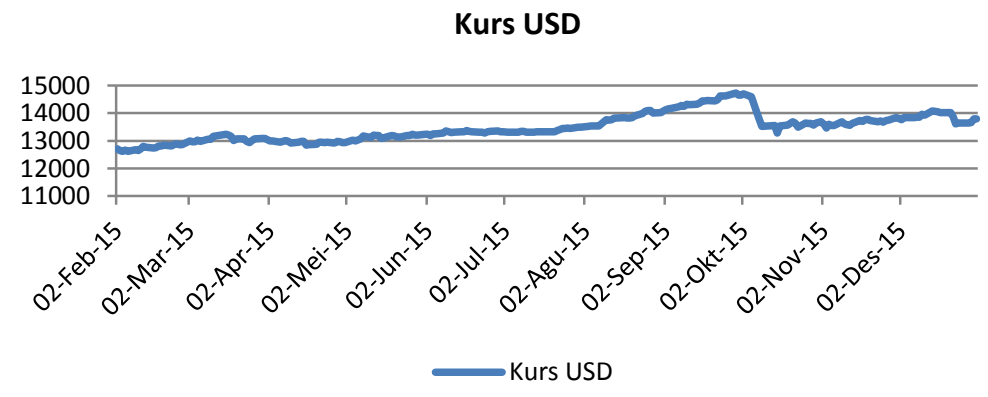

Sumber: BPS, 2015

Gambar 1

Grafik Dinamika Kurs US Dollar Tahun 2015 
Dunia investor panik sehingga menarik sejumlah investasinya di dalam negeri. Ketidakpercayaan investor, terutama investor asing akhirnya membawa fluktuasi terhadap depresiasi kurs rupiah itu sendiri.

Fluktuasi kurs menjadi sangat menganggu dalam dunia perdagangan internasional, karena harus menggunakan standar kurs yang tepat agar tidak terjadi kerugian bagi pengespor atau pengimpor. Berbagai kalangan dunia usaha telah meminta pemerintah dan otoritas moneter menjaga fluktuasi nilai tukar (kurs) rupiah terhadap dolar AS tidak terlalu tajam atau paling tinggi lima persen agar mereka masih bisa bersaing di pasar internasional maupun domestik. Adapun di sisi lain, Boediono (mantan wakil presiden Indonesia) menghendaki agar kurs terhadap dolar tidak dipatok karena dapat dijadikan ajang bagi para spekulan untuk berspekulasi yang justru akan merugikan masyarakat.

Sistem devisa bebas dan ditambah dengan penerapan sistem floating exchange rate di Indonesia sejak tahun 1997, menyebabkan pergerakan nilai tukar di pasar menjadi sangat rentan oleh pengaruh faktor-faktor ekonomi maupun non ekonomi Triyono (2008), sebaiknya pemerintah selalu melakukan usaha-usaha agar nilai tukar tetap terkendali. Baru-baru ini, pemerintah yakni kementerian keuangan menetapkan Nilai Kurs sebagai Dasar Pelunasan Bea Masuk, Pajak Pertambahan Nilai Barang dan Jasa dan Pajak Penjualan atas Barang Mewah, Pajak Ekspor, dan Pajak Penghasilan yang diterima atau diperoleh berupa uang asing harus terlebih dahulu dinilai ke dalam uang rupiah. Sebagai contoh, 1 dollar Amerika mempunya nilai dasar kurs 9.019,00 rupiah. Hal ini untuk menengarai terjadinya fluktuasi kurs, sehngga diperlukan peletakan nilai dasar kurs.

\section{METODE PENELITIAN}

Kajian pada artikel ini, terbatas pada analisis faktor eksternal, yang mempengaruhi fluktuasi kurs dollar di Indonesia, dengan menggunakan metode library research, peneliti melakukan kajian yang mendalam terhadap issue (faktor eksternal) yang terjadi di negara negara lain, dalam upayanya menstabilkan kondisi perekonomian negaranya.

Data yang digunakan dalam penelitian ini adalah data sekunder runtun waktu (time series).Data ini dibutuhkan karena penelitian ini menganalisis fenomena ekonomi secara agregat,yakni fluktuasi nilai tukar mata uang Rp/US\$ selama periode waktu 2010 sampai dengan 2015. Data yangdigunakan dalam penelitian ini adalah nilai tukar mata uang Rp/US\$. Sedangkan sumber data diperoleh dari Laporan BPS dan Financial Report dari IMF.

\section{HASIL DAN PEMBAHASAN}

Pelemahan nilai mata uang rupiah yang terjadi belakangan ini, yang sempat menyentuh angka Rp 14.728 per dollar AS, per 29 September 2015, sebagian merupakan konsekuensi dinamika faktor eksternal. Pasar keuangan internasional diwarnai penguatan dollar ASsecara global setelah berakhirnya stimulus perekonomian AS pasca krisis keuangan global 2008 (quantitative easing) oleh Bank Sentral AS (Federal Reserve atau The Fed) dan munculnya ekspektasi kenaikan fed fund rate. 


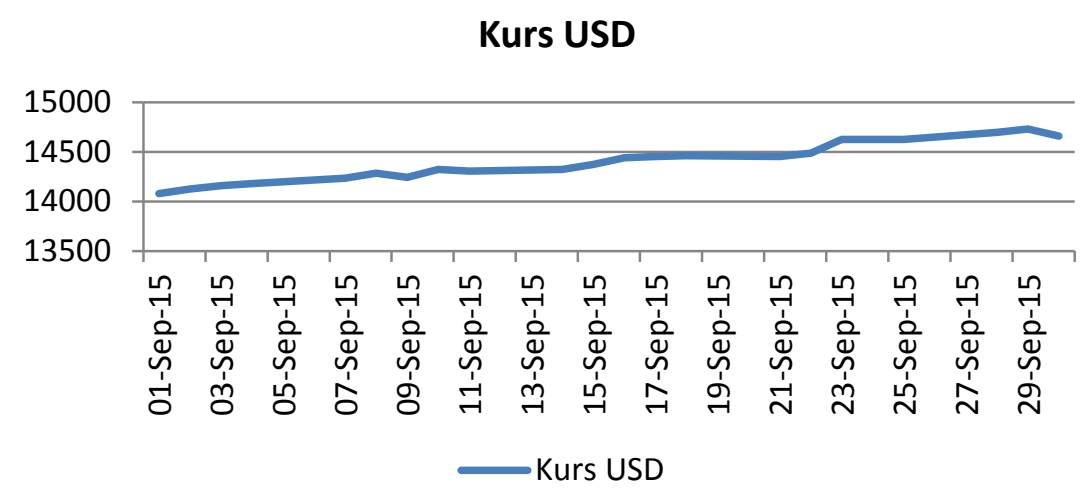

Sumber: BPS 2016

Gambar 2

Grafik harian kurs USDollar September 2015

Pada saat bersamaan, pelambatan ekonomi terjadi secara merata pada negara industri utama negara kawasan Eropa, Jepang, Tiongkok, dan India.Penurunan harga minyak dan komoditas berlanjut mendorong pengalihan dana dari komoditas ke mata uang dollar AS sebagai mata uang safe haven currency. Penguatan dollar AS terjadi secara seragam terhadap hampir semua mata uang beberapa negara. Secara umum, mata uang kuat dunia (hard currency) melemah lebih besar dibandingkan dengan negara berkembang mengingat pelambatan ekonomi lebih dalam terjadi pada negara industri utama.US dollar terus menguat terhadap mata uang utama dunia sejak awal bulan ini kecuali terhadap Yen Jepang. Nilai Yen yang juga terus menguat dan harga saham yang merosot menandakan bahwa investor sedang memburu komoditas investasi yang relatif aman, termasuk mata uang US dollar. Pasar saham merosot akibat pelaku pasar yang tidak begitu optimis pada kondisi perekonomian Amerika Serikat walau ada perbaikan.

Indeks kepercayaan konsumen Amerika Serikat memang naik ke angka tertinggi sejak Juli 2007 menurut survey dari University of Michhigan (UoM Consumer Sentiment Index) yang memberi harapan, tetapi dengan merosotnya harga saham belakangan ini analis memperkirakan kenaikan angka tersebut akan segera berbalik pada bulan selanjutnya. Import prices juga meningkat $0.5 \%$ namun tampak mulai ada tekanan inflasi pada bulan Oktober.

Ada beberapa faktor eksternal yang mempengaruhi dinamika Kurs US Dollar di Indonesia, anata ralin adalah:

1. Eropa masih bermasalah. Sementara perekonomian Amerika Serikat menunjukkan pemulihan, di benua Eropa keadaannya semakin memburuk. Para pembuat kebijakan tak bisa lagi menutupi keadaan yang sebenarnya. Jerman sebagai lokomotif perekonomian zona Eropa telah menarik beban yang cukup berat untuk pemulihan ekonomi di kawasan ini, dan kini ketika pertumbuhan ekonomi Jerman melambat akan semakin memperburuk perekonomian kawasan.Presiden bank sentral Eropa dan menteri perekonomian Jerman telah mengisyaratkan perlambatan ekonomi Jerman. 
Data perekonomian Perancis dan Yunani makin memperkuat memburuknya ekonomi di kawasan ini. ECB, IMF dan Uni Eropa yang terkesan menghindar dari persoalan bail-out Yunani hanya akan memperlambat recovery ekonomi zona Euro yang pada akhirnya akan makin memperlemah nilai mata uang Euro.

2. Yunani, salah satu negara anggota EEC, yang paling mengalami krisis perekonomian, salah satu penyebab terkurasnya cadanga US Dollar bnagara negara donomr yang berimbas kepada dinamika Kurs US dollar dinegara negara berkembang, termasuk Indonesia. Setelah bergabung dengan zona mata uang euro pada 1 Januari 2001, Yunani yang memiliki banyak utang langsung menjadi korban pertama krisis finansial global yang muncul pada 2007-2008. Imbas krisis finansial global ini tak hanya dirasakan Yunani namun juga membebani 19 negara zona euro karena harus ikut membantu membenahi perekonomian negeri itu. Risiko krisis ekonomi semakin besar ketika partai radikal sayap kiri Syriza yang menolak berbagai syarat pengucuran dana talangan memenangkan pemilu. Perlahan-lahan krisis finansial Yunan memburuk. Utang negara mencapai 107 persen dari penghasilan nasional pada 2007 menjadi 177 persen pada tahun lalu. Angka ini jauh di atas batas yang ditetapkan Uni Eropa yaitu 60 persen. Berdasarkan data badan pengelolaan utang Yunani, pada Maret tahun ini beban utang negara itu mencapai 312,7 miliar euro atau sekitar Rp 4.600 triliun alias 174,7 persen di atas GDP. Dalam kebijaksanaan moneter, dengan posisi utang Yunani tahun lalu sebesar 317 miliar euro maka IMF, salah satu kreditor terbesar negeri itu, tak bisa melanjutkan lagi untuk memberikan pinjaman.

3. Krisis fiskal Amerika Serikat. Perbaikan data ekonomi Amerika Serikat cenderung kurang mendapat tanggapan dari pasar saham disebabkan krisis fiskal atau fiscal cliff yang membayangi pemerintahan presiden Obama yang kedua. Pemerintah berusaha mengurangi defisit pada anggaran dengan kebijakan mengurangi pengeluaran belanja negara dan menaikkan pajak yang akan mengakibatkan kontraksi pada perekonomian Amerika Serikat yang sedang recovery. Dengan kebijakan ini akan bisa menghemat anggaran hingga lebih dari 600 milyard US dollar.Para investor mencemaskan kesulitan yang dihadapi Obama untuk meyakinkan Kongres agar menyetujui usulannya untuk mencari solusi dalam krisis fiskal tersebut, akibatnya pasar saham terus turun dan investor mencari komoditas yang lebih aman dengan masuk ke US dollar. Hal ini terlihat dari index US dollar (USD index) yang meningkat $0.29 \%$ pada angka 81.034 setelah sebelumnya mencapai 81.087 , tertinggi dalam 2 bulan ini.

\section{Data Ekonomi Amerika Serikat yang Membaik}

Alasan ketiga kenapa US dollar terus menguat belakangan ini adalah karena data ekonomi Amerika Serikat yang diluar dugaan terus membaik, sementara situasi zona Eropa yang tidak pasti makin memperlemah nilai mata uang Euro, 
dengan demikian, rasanya sulit mengharapkan penguatan Euro yang signifikan dalam waktu dekat.Sebagai mata uang safe haven, US dollar dan juga Yen Jepang saat ini memang sedang diuntungkan oleh risk aversion investor pada pasar saham, ditengah melemahnya mata uang utama lainnya.

\section{Melemahnya Harga Minyak Dunia}

Pelambatan ekonomi mendorong harga komoditas, termasuk minyak, terus mengalami penurunan. Penurunan permintaan terhadap minyak tidak saja dari pelambatan ekonomi dunia, tetapi juga datang dari substitusi penggunaan minyak serpih (shale oil) oleh AS.

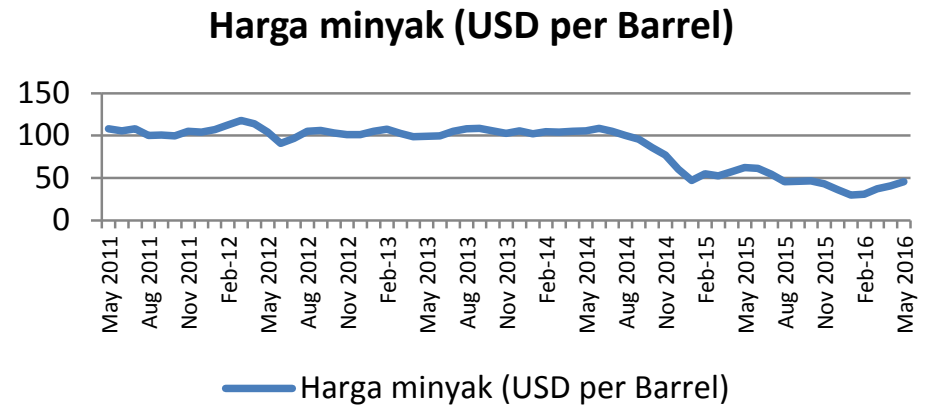

Sumber: BPS, 2016

Gambar 3

Grafik Fluktuasi Harga Minyak Dunia (USD per Barrel)

Faktor lain penyebab turunnya harga minyak adalah kombinasi antara sanksi ekonomi negara-negara barat terhadap Rusia sebagai pengekspor minyak bumi terbesar kedua di dunia akibat konflik di Ukraina dan usaha Arab Saudi melalui OPEC untuk membuat produksi minyak dari shale oil menjadi tidak ekonomis lagi dengan membuat harga minyak di bawah 60 dollar AS per barrel. Para pemilik dana akan mengalihkan dananya, dari investasi pada industri minyak mengalihkan sasaran investasinya dengan memborong US dollar.

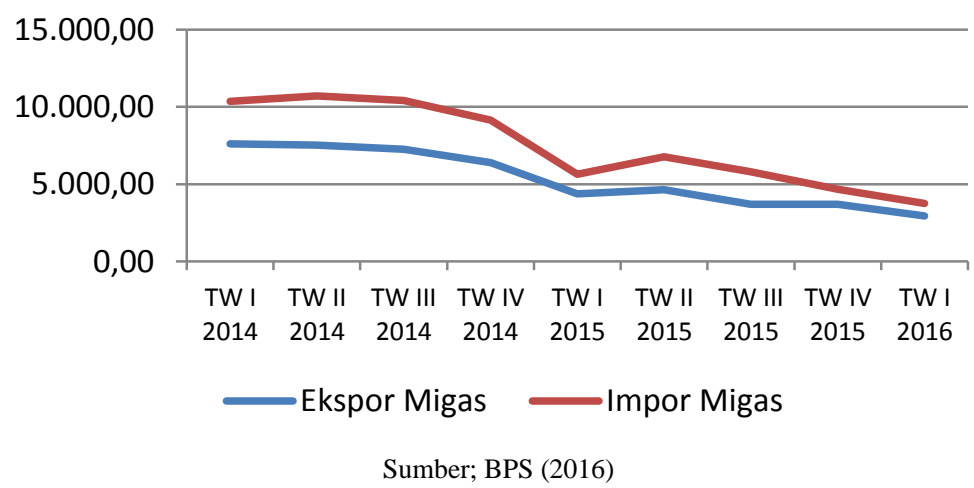

Gambar 4

Grafik Ekspor dan Impor Migas Indonesia 


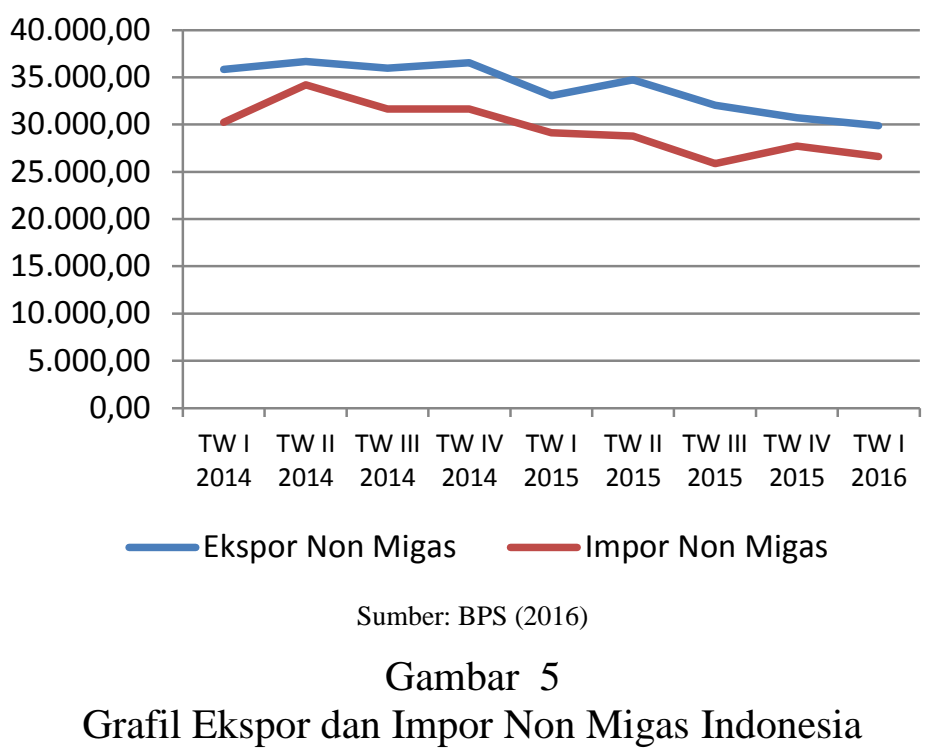

\section{Strategi Tiongkok Melemahkan Yuan}

China, menggunakan fix rate agar kurs Yuan-nya tetap lemah, atau 'undervalued'. Tujuannya agar ekspornya bisa sangat tinggi dengan harga yang kompetitif. Selain itu, agar China juga bisa terbebas dari spekulan mata uang, selain dari gejolak mata uang akibat ekonomi global. Tetapi karena tekanan dari mitra dagangnya, akhirnya kurs ini dinaikkan sedikit demi sedikit. Jadi menggunakan sistem 'managed float'. Tetapi itupun masih dibawah nilai Yuan yang sesungguhnya, jika menggunakan sistem mengambang.

Selain itu, perbankan China juga sangat kuat. Sehingga tidak ada dalil yang menyatakan sebuah perusahaan 'sehat' bisa kolaps hanya karena hutang luar negri. Begitu juga dengan semacam BI nya, bisa melakukan kontrol terhadap Yuan, dengan membeli Dollar dalam jumlah besar. Ini karena dukungan besarnya cadangan devisa China. Menguatnya Kurs Dollar terhadap Yuan terhadap Tiongkok, sangat mempengaruhi kuatnya Kurs Dollar terhadap Rupiah. Karena transaksi bisnis antara Indonesia dengan Tiongkok menggunakan US\$ sebagai alat transaksi.

\section{E. SIMPULAN}

Dari uraian yang sudah dipaparkan diatas, beberapa simpulan yang dapat dapat dicatat, antara lain adalah:

1. Faktor eksternal sangat mempengaruhi dinamika US\$ terhadap Ripah, dan berpengaruh terhadap pertumbuhan ekonomi Indonesia.

2. Pengaruh yang dialami kondisi perekonomian Indonesia, diakibatkan karena banyak bahan baku industri, masih diperoleh dari luar negeri, yang menggunakan alat transaksi dengan US\$.

3. Transaksi melalui US\$ tersebut pada butir 2, sangat mempengaruhi biaya produksi, dan akhirnya produk yang dihasilkan sulit bersaing dengan produk 
dari negara lain, yang mampu menciptakan bahan baku industrinya secara mandiri.

4. Agar Indonesia bisa bersaing dalam dunia perdaganan Internasional, fluktuasi nilai tukar (kurs) rupiah terhadap dolar AS tidak terlalu tajam atau paling tinggi lima persen agar mereka masih bisa bersaing di pasar internasional maupun domestik.

5. Kurs dollar tidak boleh dipatok, karena karena dapat dijadikan ajang spekulasi bagi para spekulan, yang akan merugikan masyarakat. Karenanya, dengan kebijaksanaan floating rate, merupakan pilihan yang tepat ditengah kondisi perekonomian yang tidak stabil. 


\section{DAFTAR PUSTAKA}

Adam, Cristopher M, 1991. Exchange Rate Volatility, Monetary Policy Adjustment and Price Hysteresis,

Baldwin, Richard, 1988.Sunk Cost Hysteresis, National Bureau of Economic Research WorkingPaper, No. 2911,

Baldwin, R.E. dan P. Krugman, 1989. Persistent Trade Effects of Large Exchange Rate Shocks, Quarterly Journal of Economics, 104:635- 655

[BPS], 2016, Dinamika Kurs USDollar, BPS dalam angka, Badan Pusat Statistik

Dornbusch, Rudiger, 1987,'Expectations and Exchange Rate Dynamics", Journal of Political Economy, 84, 1976, 1161-1176 Economic Review,77:93-106 1987.Exchange Rate and Process, The American

Foot, K.A dan P.D Kemplerer, 1989. Exchange Rate Pass-Through When Market Share Matters, The American Economic Review, 79: 637-654

Mukhlis, Imam (2011), Impacts of Exchange Rate Volatility on Sectoral Trade in the Mercosur", Paper, Prepared forJournal of Indonesian Applied Economics Vol. 5 No. 2 Oktober 2011, 172-182

Nilai Tukar Fleksibel: Suatu Pemikiran untuk Penerapannya di Indonesia, Bulletin Ekonomi dan Moneter Perbankan, Juli:1-23

Periphery, Working Paper Series, No.773, European Central Bank, July:1-47

Vergil, Hasan. 2002. Exchange Rate Volatility in Turkey and its Effect on Trade Flow, Journal of Economics and Social Research, Vol. 4(1):83-99

Zainal, Arindra Artasya. 2004. Exchange Rate Pass-Through, Exchange Rate Volatility, and Their Impact on Export: Evidence from Indonesian Data, Disertasi, Kansas University http:/www.imf.org,diakses pada tanggal 20 September

Muelgini, Yoke Muelgini, Dr., M.Sc. Sistem Devisa Dan Nilai Tukar: Kebijakan Di Indonesia. Pusat Pendidikan Dan Studi Kebanksentralan (PPSK). Fakultas Ekonomi Universitas Lampung.

Triyono. Analisis Perubahan Kurs Rupiah Jurnal Ekonomi Pembangunan, Vol. 9, No. 2, Desember 2008

Ulfa, Almizan. Indonesia Satu Dan Stabilitas Kurs Rupiah: Analisis Stabilitas Exchange Rates Indonesia Pasca Krisis 1997. Jurnal Keuangan dan Moneter, Volume 6 Nomor 2.

Keputusan Menteri Keuangan Republik Indonesia Nomor 12/Km.11/2010 Tanggal 30 April 2010 
Undang-Undang Republik Indonesia Nomor 3 Tahun 2004 Tentang Perubahan Atas Undang-Undang Republik Indonesia Nomor 23 Tahun 1999 Tentang Bank Indonesia 